\title{
Sistem Informasi Penjualan Furniture Berbasis Web
}

\author{
${ }^{1}$ Erni Ermawati, ${ }^{2}$ Nurul Ichsan, ${ }^{3}$ Tri Wahyuni \\ Email11erni.ert@bsi.ac.id, ${ }^{2}$ nurul.nrc@bsi.ac.id, ${ }^{3}$ tri.twy@bsi.ac.id
}

\begin{abstract}
Abstrak
Jugala Furniture adalah perusahaan dagang yang bergerak di bidang penjualan furniture perlengkapan alat-alat rumah tangga seperti meja, kursi, lemari, tempat tidur dan lain-lain. Perusahaan Jugala Furniture masih menggunakan sistem manual mulai dari pemesanan barang, perhitungan penjualan, perhitungan stok barang dan pembuatan laporan. Hal ini seringkali menimbulkan masalah dalam keakuratan data, karena Jugala Furniture belum memiliki sistem yang terkomputerisasi terutama dalam kegiatan penjualannya. Maka dibutuhkan satu rangkaian rancangan sistem informasi yang kompleks untuk mengatasi masalah tersebut. Tujuan dari penelitian ini adalah untuk membangun rancangan dan implementasi sistem informasi penjualan furniture dengan memanfaatkan website sebagai media promosi dalam penjualan online. Pembuatan website berbasis E-Commerce merupakan solusi untuk meningkatkan kinerja perusahaan dalam sektor peningkatan kualitas informasi dan pemanfaatan waktu yang lebih efisien. Sistem informasi ini dibuat dengan menggunakan metode Rapid Application Development dan dibangun dengan menggunakan bahasa php dan Mysql. Hasil dari penelitian ini menghasilkan media promosi, pemesanan dan pembelian berbasis web yang dapat digunakan oleh perusahaan sebagai bentuk pelayanan pemesanan dan pembelian furniture secara online dan bisa digunakan sebagai media promosi.
\end{abstract}

Kata kunci: E-Commerce, Furniture, Rapid Application Development

\begin{abstract}
Jugala Furniture is a trading company engaged in the sale of furniture equipment household appliances such as tables, chairs, cabinets, beds and others. Jugala Furniture still uses manual system from ordering goods, sales calculation, inventory calculation and reporting. this makes the problem in the accuracy of data, because Jugala Furniture does not have a computerized system, especially in sales activities. Therefore Jugala Furniture requires a complex information system design to solve the problem. The purpose of this research is to build the design and implementation of information systems furniture sales by utilizing the website as a promotion in online sales. ECommerce-based website creation is a solution to improve company performance in the sector of information quality improvement and more efficient utilization of time. This information system is made by Rapid Application Development method and built using php and Mysql language. The result of this research is media of promotion, ordering and purchasing of web-based that can be used by company as service form ordering and purchasing of furniture online and can be used as promotion media.
\end{abstract}

Keywords: E-Commerce, Furniture, Rapid Application Development

Jurnal Interkom Vol. 13 No. 3 - Oktober 2018 


\section{Pendahuluan}

Merujuk data Frost \& Sullivan (Indonesia Telecom Outlook Indonesia-Go Online, 2012), pendapatan transaksi e-commerce di Indonesia mencapai USD 120 juta pada 2010 dan akan menjadi USD 650 juta pada 2015. Sementara itu, menurut Asosiasi Penyelenggara Jasa Internet Indonesia (APJII), jumlah pengguna internet di Indonesia pada 2012 mencapai 63 juta dan diprediksi menjadi 82 juta di akhir 2013.

Perusahaan Jugala Furniture yang berada di jalan Caringin Cikukulu Km 4 Sukabumi merupakan salah satu perusahaan yang bergerak dalam bidang penjualan furniture perlengkapan alat-alat rumah tangga seperti meja, kursi, lemari, tempat tidur dan lain-lain. Jugala Furniture masih mengalami berbagai permasalahan mulai dari terbatasnya tenaga/karyawan profesional, serta kurangnya media promosi dan informasi produk kepada konsumen yang berimbas kepada lambatnya kemajuan roda bisnis pada perusahaan, hal tersebut tentu menimbulkan sebuah masalah yang harus segera diselesaikan.

Perkembangan teknologi semakin pesat, sama halnya dengan perkembangan sistem informasi. Internet sudah menjadi trend baru manusia masa kini. Perkembangan komputer membuat para ahli komputer mencoba membangun suatu sistem komputer yang dapat membantu para ahli dalam mengambil keputusan, sehingga dapat mengurangi resiko kesalahan yang dapat terjadi karena beberapa kekurangan yang dimiliki oleh manusia.

Berdasarkan permasalahan yang dibahas sebelumnya di Perusahaan Jugala Furniture, selain terkendala dengan sistem yang masih manual, pemilik/owner Jugala Furniture ingin meningkatkan kembali jumlah pengunjung yang ada dan juga berkeinginan untuk memperluas jangkauan bisnisnya namun tidak memiliki modal yang cukup. Maka dibutuhkan satu rangkaian rancangan dan implementasi dari sistem informasi yang kompleks untuk mengatasi masalah seperti sistem yang masih manual mulai dari pemesanan barang, perhitungan penjualan, perhitungan stok barang dan pembuatan laporan yang seringkali menimbulkan masalah dalam keakuratan data dengan cara memanfaatkan website sebagai media promosi dalam penjualan online.

Melalui penelitian ini akan dibangun strategi perancangan dan implementasi sistem informasi melalui pembuatan website berbasis $e$ commerce sebagai solusi untuk meningkatkan kinerja perusahaan dalam sektor peningkatan kualitas informasi dan pemanfaatan waktu yang lebih efisien. Sistem informasi ini dibuat dengan menggunakan metode Rapid Application Development dan dibangun dengan menggunakan bahasa php dan Mysql.

\section{Tinjauan Pustaka}

\section{Sistem Informasi}

Menurut Herman, Lisa Amelia dan Daswirman (2017), "sistem adalah suatu kerangka dari prosedur-prosedur yang saling berhubungan, yang disusun sesuai dengan skema yang menyeluruh untuk melaksanakan suatu kegiatan atau fungsi utama dari perusahaan yang dihasilkan oleh suatu proses tertentu".

Sedangkan menurut Susanto (2009), "informasi merupakan data yang telah diproses menjadi bentuk yang memiliki arti bagi penerima dan dapat berupa fakta dan suatu nilai yang bermanfaat".

Menurut Sutarman (2012), "sistem informasi adalah sistem yang dapat didefinisikan dengan mengumpulkan, memproses, menyimpan, menganalisis, menyebarkan informasi untuk tujuan tertentu“". Selain itu, menurut Sihite, Julian Anugrah dan Meliana Christianti (2017), "Sistem Informasi merupakan sistem yang terintegrasi untuk menyediakan informasi untuk mendukung operasi, manajemen dalam suatu organisasi”.

\section{E-Commerce}

Menurut Kabanda, S., dan Brown, I. (2017), "e-commerce menyediakan kemampuan membeli dan menjual barang menggunakan internet atau media pelayanan online yang lain". Menurut Hakim, Fitro Nur dan Achmad Solechan (2017), e-commerce adalah aktivitas dalam transaksi, pembelian, penjualan dalam bisnis dan pertukaran informasi secara elektronik dengan memanfaatkan jaringan internet yang memberikan manfaat agar proses 
bisnis perdagangan yang berjalan menjadi lebih efektif dan efisien".

Kegiatan e-commerce meliputi proses pembelian, penjualan, pelayanan, dan pengembangan lainnya dengan memanfaatkan media internet sebagai alat komunikasi efektif antara penjual dengan pembeli. Aliran cepat untuk situs e-commerce dapat dibangun melalui desain web yang efektif. Desain web yang cerdas akan memberikan pengalaman pengguna yang luar biasa untuk portal e-commerce dan sangat penting untuk keberhasilan platform $e$ commerce.

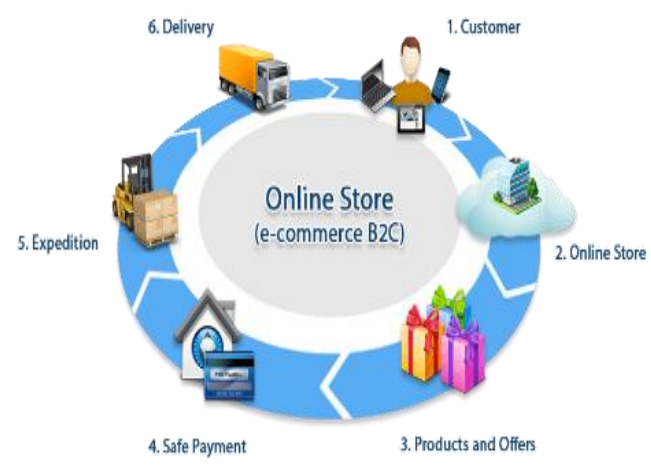

Gambar 1. Aliran Swift E-Commerce

\section{Rapid Application Development}

Menurut Najoan, Xaverius B.N., et.al (2016), "Rapid Application Development (RAD) adalah sebuah metodologi yang membangun sebuah prototype dimana dalam kasus ini menekankan pada siklus pembangunan yang singkat dan cepat, waktu yang singkat merupakan batasan penting dalam model ini". Metode RAD memiliki tiga tahapan utama seperti terlihat pada gambar di bawah ini:

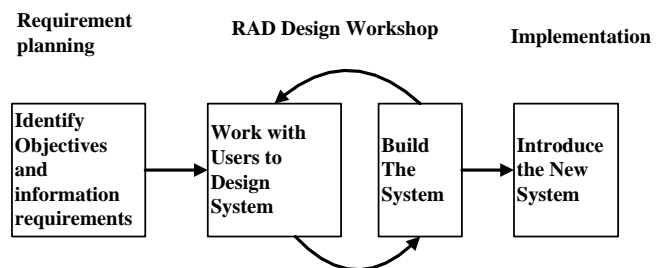

Gambar 2. Tahapan RAD

\section{Use Case Diagram}

Menurut Rosa dan Shalahuddin (2011), "use case atau diagram use case merupakan pemodelan untuk kelakukan (behavior) sistem informasi yang akan dibuat". Use case mendeskripsikan sebuah interaksi antara satu atau lebih aktor dengan dengan sistem informasi yang akan dibuat.

\section{Activity Diagram}

Menurut Rosa dan Shalahuddin (2011), "diagram aktifitas atau activity diagram menggambarkan workflow (aliran kerja) atau aktivitas dari sebuah sistem atau proses bisnis atau menu yang ada pada perangkat".

\section{Sequence Diagram}

Menurut Rosa dan Shalahuddin (2011), "diagram sekuen menggambarkan kelakuan objek pada use case dengan mendeskripsikan waktu hidup objek dan message yang akan dikirimkan dan diterima antar objek".

\section{Class Diagram}

Menurut Rosa dan Shalahuddin (2011), "diagram kelas atau class diagram menggambarkan struktur sistem dari segi pendefinisan kelas-kelas yang akan dibuat untuk membangun sistem".

\section{Deployment Diagram}

Menurut Rosa dan Shalahuddin (2011), "diagram deployment atau deployment diagram menunjukkan konfigurasi komponen dalam proses eksekusi aplikasi”.

\section{Metode Penelitian}

\section{Tahapan Penelitian}

Tahapan-tahapan yang dilakukan dalam penelitian ini dapat direncanakan dan diselesaikan dengan 5 tahapan yaitu: analisa kebutuhan dan identifikasi masalah, studi Literatur, perancangan aplikasi/website, Implementasi, hasil dan kesimpulan penelitian, seperti pada gambar dibawah ini: 


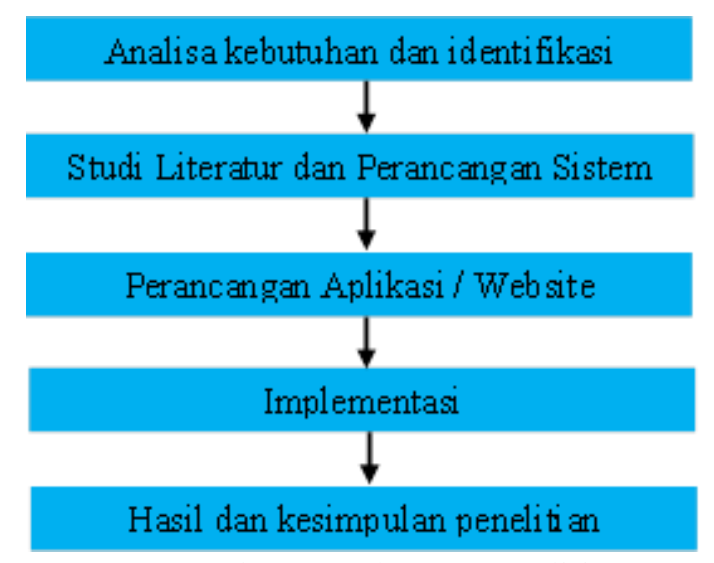

Gambar 3. Tahapan Penelitian

\section{Metode Pengembangan Sistem}

Metode perancangan sistem informasi penjualan furniture berbasis web yang digunakan dalam penelitian ini menggunakan metode Rapid Application Development (RAD) salah satu metode pengembangan dengan pendekatan berorientasi objek yang bertujuan menghasilkan sebuah sistem dengan waktu pengerjaan aplikasi yang singkat dan proses agar sesegera mungkin memberdayakan sistem perangkat lunak tersebut dengan tepat dan cepat. Terdapat 3 fase dalam penelitian ini seperti yang bisa dilihat di gambar 2 .

\section{Rencana Kebutuhan}

Pada tahapan ini, user dan analyst melakukan pertemuan untuk melakukan identifikasi kebutuhan informasi untuk mencapai tujuan.

\section{Proses Desain}

Pada tahap ini dilakukan proses desain dan perbaikan apabila masih terdapat ketidak sesuaian desain yang diinginkan user. Biasanya user dan analyst duduk melingkar dimana masing-masing orang bisa melihat satu dengan yang lain tanpa ada halangan.

\section{Implementasi}

Setelah desain dari sistem yang akan dibuat sudah disetujui, maka pada tahap ini programmer mengembangkan desain menjadi suatu program. Pembuatan program bisa memakan waktu lebih lama dari tahapan sebelumnya, karena setiap tools-tools yang dimasukan kedalam sebuah program harus memiliki fungsi yang dapat dimanfaatkan dengan baik oleh user nantinya.
Setelah program selesai dengan baik maka dilakukan proses pengujian. Tampilan, tata letak setiap tools yang terdapat dalam program diuji apakah terdapat kesalahan atau tidak sebelum diaplikasikan pada suatu organisasi. Selanjutnya user memberikan tanggapan akan sistem yang dibuat secara keseluruhan.

\section{Hasil dan Pembahasan}

\section{Analisa Sistem Berjalan}

Perancangan website berbasis $E$ Commerce dalam penelitian ini dibuat sebagai solusi untuk meningkatkan kinerja perusahaan dalam sektor peningkatan kualitas informasi dan pemanfaatan waktu yang lebih efisien yang bisa digunakan sebagai alat media promosi dan bisa dimanfaatkan pebisnis untuk memasarkan produk serta menarik pelanggan potensial dari berbagai wilayah di Indonesia, selain itu bisa digunakan untuk pemesanan dan pembelian furniture secara online yang dikembangkan melalui metode Rapid Application Development dan dibangun dengan menggunakan bahasa $p h p$ dan Mysql. Berikut adalah proses bisnis sebelum diusulkannya sistem yang terkomputerisasi.

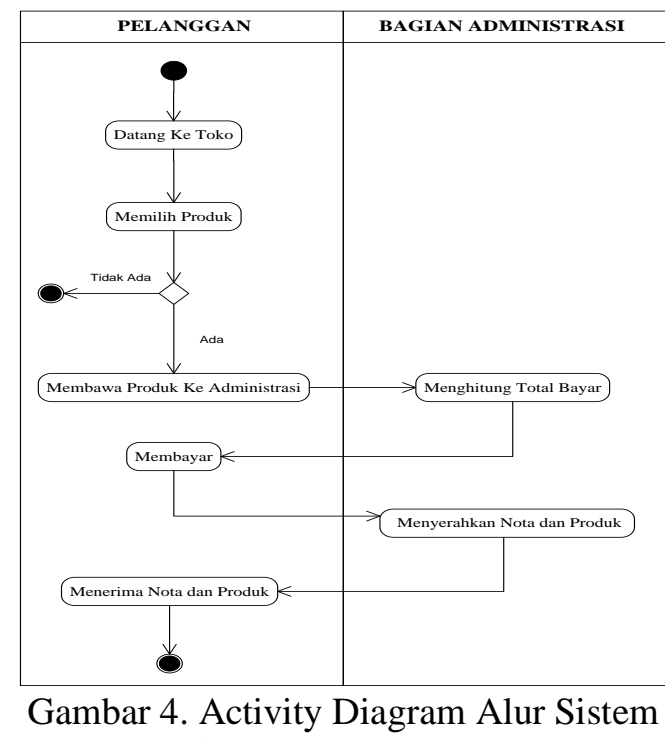

Berjalan Jugala Furniture

\section{Implementasi RAD}

Berikut adalah implementasi dan penerapan terhadap perancangan sistem informasi penjualan furniture berbasis $e$ commerce dengan pengembangan metode RAD: 


\section{Fase Rencana Kebutuhan}

Analisa kebutuhan sistem untuk website sistem penjualan online Jugala Furniture yaitu:

Tabel 2. Analisa Kebutuhan User

\begin{tabular}{|c|l|}
\hline No & \multicolumn{1}{|c|}{ Kebutuhan User } \\
\hline 1 & Beranda \\
\hline 2 & Login \\
\hline 3 & Produk \\
\hline 4 & Katalog \\
\hline 5 & Akun \\
\hline 6 & Kontak \\
\hline 7 & Keranjang \\
\hline 8 & Logout \\
\hline
\end{tabular}

Tabel 3. Analisa Kebutuhan Admin

\begin{tabular}{|c|l|}
\hline No & \multicolumn{1}{|c|}{ Kebutuhan Admin } \\
\hline 1 & Login \\
\hline 2 & Beranda \\
\hline 3 & Katalog (produk, email, admin) \\
\hline 4 & Ekstensi (kategori, provinsi, shipping) \\
\hline 5 & $\begin{array}{l}\text { Penjualan (pesanan, konfirmasi, } \\
\text { konsumen) }\end{array}$ \\
\hline 6 & Apperance (banner, slider) \\
\hline 7 & Lihat web \\
\hline 8 & Logout \\
\hline
\end{tabular}

\section{Fase Proses Desain}

Pada tahap ini di fase desain akan diterapkan strategi back-end dan front-end. Dalam fase ini selanjutnya dibuat arsitektur website yang digunakan untuk memberikan kemudahan bagi pengguna atau user dengan pemodelan sistem berbasis objek yang digambarkan menggunakan UML (use case diagram, activity diagram, sequence diagram class diagram dan deployment diagram).

\section{Fase Implementasi}

Fase implementasi untuk menunjukkan platform, hardware, dan software yang digunakan. Pada tahap ini programmer mengembangkan desain menjadi suatu program.

Pembuatan program bisa memakan waktu lebih lama dari tahapan sebelumnya, karena setiap tools-tools yang dimasukan kedalam sebuah program harus memiliki fungsi yang dapat dimanfaatkan dengan baik oleh user nantinya.

\section{Entity Relationship Diagram}

ERD merupakan suatu model jaringan yang menggunakan susunan data yang disimpan pada system secara abstrak. ERD juga menggambarkan hubungan antara satu entitas yang memiliki sejumlah atribut dengan entitas yang lain dalam suatu sistem yang terintegrasi. Berikut adalah rancangannya:

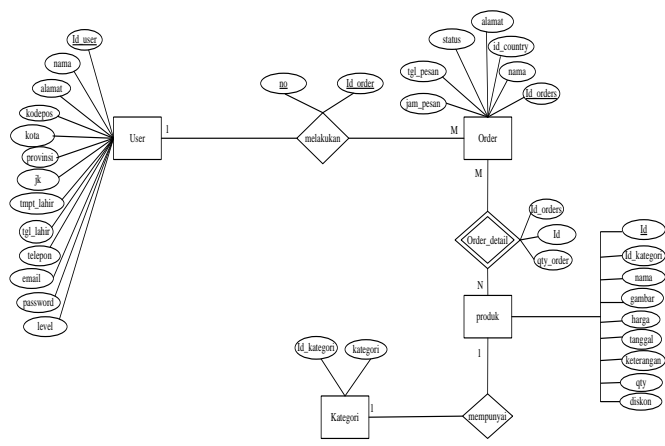

Gambar 5. Entity Relationship Diagram

\section{Interface}

1. Halaman Login

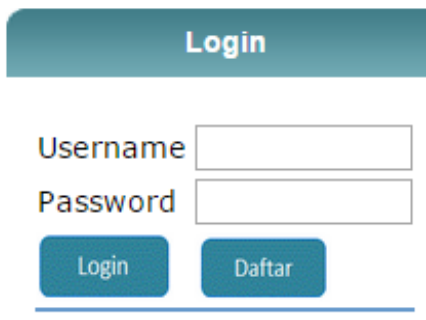

Gambar 6. Halaman Login

2. Halaman Beranda User

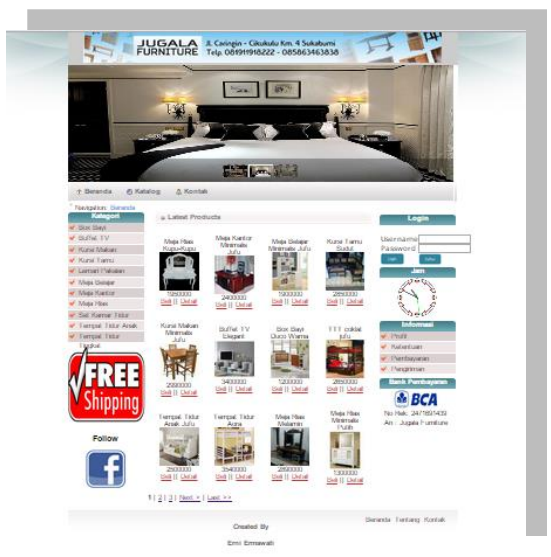

Gambar 7. Halaman Beranda User 
3. Halaman Login Admin

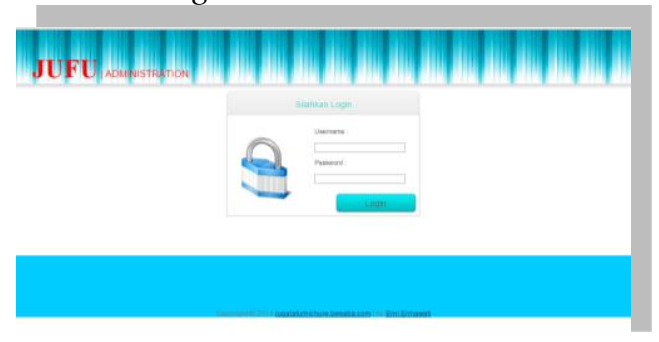

Gambar 8. Halaman Login Admin

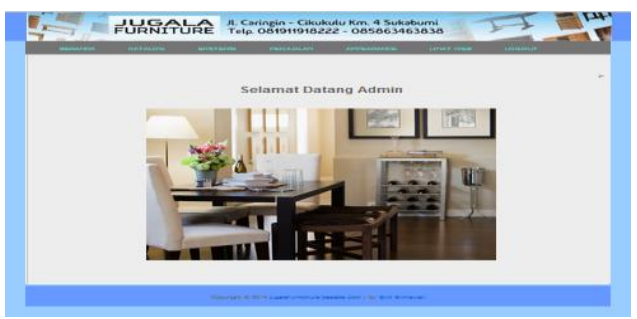

Gambar 9. Beranda Admin

\section{Implementasi Pengujian Unit}

Uji coba yang dilakukan untuk melihat apakah fungsi-fungsi dalam website sudah sesuai yang diharapkan adalah dengan menggunakan setiap fitur yang ada dalam website dan membuat skenario dari pemakaian atau kondisi pada website ini, dan sekaligus menjadi tahap akhir dari RAD. Hasil uji coba tersebut bisa dilihat melalui uji coba blackbox salah satunya melalui pengujian terhadap form login member.

Tabel 4. Hasil Pengujian Black Box Testing Halaman Login Member

\begin{tabular}{|c|c|c|c|c|c|}
\hline No & $\begin{array}{c}\text { Skenario } \\
\text { Pengujian }\end{array}$ & Test Case & $\begin{array}{l}\text { Hasil Yang } \\
\text { Diharapkan }\end{array}$ & $\begin{array}{c}\text { Hasil } \\
\text { Pengujian }\end{array}$ & Kesimpulan \\
\hline 1 & $\begin{array}{l}\text { Email dan } \\
\text { password tidak } \\
\text { diisi } \\
\text { kemudian klik } \\
\text { tombol login }\end{array}$ & $\begin{array}{l}\text { Email: } \\
\text { (kosong) } \\
\text { Password: } \\
\text { (kosong) }\end{array}$ & $\begin{array}{lr}\text { Sistem akan } & \text { akan } \\
\text { menolak akses user } \\
\text { dan menampilkan } \\
\text { "Email atau } \\
\text { Password yang anda } \\
\text { masukkan salah coba } \\
\text { lagi atau hubungi } \\
\text { admin!!" }\end{array}$ & $\begin{array}{c}\text { Sesuai } \\
\text { Harapan }\end{array}$ & Valid \\
\hline 2 & $\begin{array}{l}\text { Mengetikkan } \\
\text { email dan } \\
\text { password } \\
\text { tidak diisi } \\
\text { kemudian klik } \\
\text { tombol login }\end{array}$ & $\begin{array}{l}\text { Email: } \\
\text { erniermawati3 } \\
\text { 39@gmail.com } \\
\text { Password: } \\
\text { (kosong) }\end{array}$ & \begin{tabular}{|lr} 
Sistem akan & akan \\
menolak akses user \\
dan menampilkan \\
"Email ratau \\
Password yang anda \\
masukkan salah coba \\
lagi ataul hubungi \\
admin!!"” \\
\end{tabular} & $\begin{array}{c}\text { Sesuai } \\
\text { Harapan }\end{array}$ & Valid \\
\hline 3 & $\begin{array}{lr}\text { Email } & \text { tidak di } \\
\text { isi dan password } \\
\text { diisi } & \text { kemudian } \\
\text { klik } & \text { tombol } \\
\text { login } & \end{array}$ & \begin{tabular}{|l|} 
email: \\
(kosong) \\
Password: \\
erniermawati
\end{tabular} & $\begin{array}{|lr|}\text { Sistem } & \text { akan } \\
\text { menolak akses user } \\
\text { dan menampilkan } \\
\text { "“Email } & \text { atau } \\
\text { Password yang anda } \\
\text { masukkan salah coba } \\
\text { lagi atau hubungi } \\
\text { admin!!"” hubi }\end{array}$ & $\begin{array}{c}\text { Sesuai } \\
\text { Harapan }\end{array}$ & Valid \\
\hline 4 & $\begin{array}{l}\text { Mengetikkan } \\
\text { salah satu } \\
\text { kondisi salah } \\
\text { pada email atau } \\
\text { password } \\
\text { kemudian klik } \\
\text { tombol login }\end{array}$ & $\begin{array}{l}\text { Email: } \\
\text { erniermawati3 } \\
\text { 39@gmail.com } \\
\text { (benar) } \\
\text { Password: erni } \\
\text { (salah) }\end{array}$ & \begin{tabular}{|l} 
Sistem akan \\
menolak \\
akses user dan \\
menampilkan "Email \\
atau Password yang \\
anda masukkan salah \\
coba lagi atau \\
hubungi admin!!"' \\
\end{tabular} & $\begin{array}{c}\text { Sesuai } \\
\text { Harapan }\end{array}$ & Valid \\
\hline
\end{tabular}

\begin{tabular}{|l|l|l|l|l|c|}
\hline 5 & Mengetikkan & Email : & Sistem menerima & & \\
& email dan & erniermawati3 & akses login dan & & \\
& password & 39@gmail.com & kemudian langsung & & \\
& dengan data & (benar) & menampilkan index & Sesuai & Valid \\
& yang & Password: & akun. & & \\
& benar kemudian & ermiermawati & & \\
& llik tombol & (benar) & & & \\
login & & & & \\
\hline
\end{tabular}

\section{Kesimpulan dan Saran}

\section{Kesimpulan}

Beberapa kesimpulan yang dapat ditarik diantaranya:

1. Sistem yang berjalan pada perusahaan Jugala Furniture saat ini masih dilakukan secara manual sehingga menimbulkan berbagai masalah terutama pada penyimpan data lama, penjualan dan penyebaran informasi baru.

2. Penggunaan sistem informasi berbasis web dinilai lebih efisien dan efektif dibandingkan proses manual sehingga informasi yang akan disampaikan dapat diakses dengan mudah oleh user, serta update data yang bisa dilakukan kapanpun sesuai dengan keinginan owner.

3. Penyampaian informasi melalui website mampu menyediakan informasi dalam bentuk teks dan gambar, yang membuat suatu informasi lebih menarik untuk dilihat.

\section{Saran}

Penelitian selanjutnya pengembang bisa mengembangkan prototype website dengan menggunakan framework bootsrap atau menggabungkan bootstrap dengan framework Laravel atau Code Igniter yang sudah mulai banyak digunakan sampai saat ini. Bisa juga dengan menambahkan CRM (Customer Relationship Management) agar mempermudah pengelolaan hubungan antara perusahaan dengan customer.

\section{Daftar Pustaka}

Wulandari, Dwi. 2013. Jawab Pertumbuhan ECommerce, SAS Hadirkan SAS Visual Analytics. Diambil Dari:

Http://Mix.Co.Id/Headline/JawabPertumbuhan-E-Commerce-Sas- 
Hadirkan-Sas-Visual-Analytics/ (25 April 2015).

Mulyani, W., \& Purnama, B. E. (2015). Pembangunan Sistem Informasi Data Balita Pada Posyandu Desa Ploso Kecamatan Punung Kabupaten Pacitan, 7(2), 15-19. Taufik Rahman

Suryanto, A., Paramita, O., Pribadi, F. S., \& Gizi, S. (n.d.). Sistem Layanan Monitoring Status Gizi Anak, 1-12. Sutanta

Herman, Lisa Amelia dan Daswirman. 2017. Analisis Faktor-Faktor yang Mempengaruhi Kualitas Laporan Keuangan Pemerintah Daerah (Studi Empiris Pada Pemerintah Daerah Kota Payakumbuh). Jurnal Pundi, Vol. 01, No. 02, Juli 2017.

A. Susanto, Sistem Informasi Manajemen Dan Konsep dan Pengembangannya, Bandung, Lingga Jati, 2009, p. 13.

Sutarman, Buku Pengantar Teknologi Informasi, Jakarta, Bumi Aksara, 2012, p. 51. Martin \& Tanamah

Sihite, Julian Anugrah dan Meliana Christianti. 2017. Sistem Informasi Pengelolaan Daftar Kehadiran dan Jadwal Pembicara Berbasis Website Dengan Mail Gateway Pada Komunitas JC Bandung. e-ISSN: 2443-2229. Jurnal Teknik Informatika dan Sistem Informasi, Volume 3 Nomor 2 Agustus 2017.

Kabanda, S., \& Brown, I. 2017. A Structuration Analysis of Small and Medium Enterprise (SME) Adoption of E-commerce: The Case of Tanzania. Telematics and Informatics, 34(4): 118-132.

Hakim, Fitro Nur dan Achmad Solechan. 2017. Perancangan Sistem Informasi Penjualan Online Pada UKM Industri Monel Desa Kriyan Jepara. JURNAL INFORMATIKA UPGRIS Vol. 3, No. 1, (2017) P/E-ISSN: 2460-4801/2447-6645.

Najoan, Xaverius B.N., et.al. Sistem Informasi Akademik Berbasis Mobile Web Menggunakan Pendekatan Metodologi RAD (Studi Kasus: Universitas Sam Ratulangi). E-Journal Teknik Elektro dan Komputer. 24-35. Vol. 5 No. 5 Okt-Des 2016.
Rosa dan Shalahuddin. 2011. Modul Pembelajaran Rakayasa Perangkat Lunak (Terstruktur dan Berorientasi Objek). Bandung:Modula.

Tanjung, Intan S Yatana S, Mardhiah Fadhli dan Ibnu Surya, Implementasi E-Commerce Menggunakan Metode UCD (User Centered Design) Berbasis Web, Jurnal Aksara Komputer Terapan Politeknik Caltex Riau Vol. 6, No. 2, Tahun 2017

Wandy, Sandy, Wawan Yunanto dan Istianah Muslim, Rancang Bangun Sistem ECommerce Berbasis Web Pada Pauli SPA, Jurnal Aksara Komputer Terapan Politeknik Caltex Riau Vol. 6, No. 2, Tahun 2017

M.T.I, Elisabet Y.A, Ratnasari, Perancangan Aplikasi E-Commerce Pada Toko Jam Tangan Alexander Cristie, Jurnal TAM (Technology Acceptance Model), 20-25, Volume 2 Juli 2014

Handayani, Sri Peni Mugi, Bambang Eka Purnama, Pembuatan Website ECommerce Pada Distro Java Trend, Seminar Riset Unggulan Nasional Informatika dan Komputer FTI UNSA 2013, 18-24, Vol 2 No 1 - Maret 2013

Kosasi, Sandy dan I Dewa Ayu Eka Yuliani. Penerapan Rapid Application Development pada Sistem Penjualan Sepeda Online. Jurnal SIMETRIS, 27-36, Vol 6 No 1 April 2015. 